\title{
Contato improvisação (contact improvisation) um diálogo em dança
}

Fernanda Hübner de Carvalho Leite

\begin{abstract}
Resumo: Este estudo é uma revisão bibliográfica que apresenta o Contact Improvisation, um estilo de dança criado no início dos anos 70 nos EUA e que vem sendo desenvolvido em diversos países como uma prática cujos princípios trazem mudanças de padrões na dança e abordam atuais discussões sobre corpo, educação, questões de gênero, sexualidade, identidade e diferença. Acerca do Contact Improvisation existe significativa produção intelectual materializada em um periódico específico principal (Contact Quarterly), revistas e jornais de dança, páginas da internet, vídeos, teses e livros além de encontros em seminários e festivais.
\end{abstract}

Palavras-chave: dança, corpo, educação.

O presente trabalho é uma revisão bibliográfica sobre a dança de origem americana Contact Improvisation, mais conhecida no Brasil como Contato Improvisação, tomando como referência principal o livro "Sharing the dance - contact improvisation and american culture", de Cynthia Jean Novack. ${ }^{1}$ A proposta é traçar um histórico desde a criação do Contato Improvisação, observando o desenvolvimento, modificações e algumas tendências atuais deste estilo de movimento. São abordados aspectos culturais, sociais e principalmente de ensino e aprendizagem desta prática.

A importância do Contato Improvisação reside nos seguintes aspectos: sua influência na dança e no teatro contemporâneos; a significativa produção intelectual materializada em um periódico específico principal (Contact Quarterly), revistas e jornais de dança,

1 A antropóloga e bailarina Cynthia Jean Novack transformou sua tese de doutorado na School of Arts and Sciences da Columbia University, concluída em 1986 intitulada "Sharing the dance - an ethnography of contact improvisation", no livro publicado em 1990 "Sharing the dance - contact improvisation and american culture".

2 Por exemplo: os jornais Movement Research de Nova lorque, La Porta Voz de Barcelona, Novelles de Danse de Bruxelas, Proximity da Austrália.

Movimento, Porto Alegre, v. 11, n. 2, p.89-1 10, maio/agosto de 2005 
páginas e grupos da internet, ${ }^{3}$ conferências, ${ }^{4}$ vídeos, ${ }^{5}$ trabalhos acadêmicos e livros; ${ }^{6}$ o grande número de praticantes espalhados em diversos países cujo nome e endereço constam publicados no periódico supracitado; as peculiaridades conceituais que abordam e discutem questões sociais e culturais de corpo, dança, arte, educação, gênero, sexualidade, sensualidade, identidade e diferença.

Porém, aqui no Brasil, ainda são escassas, se não inexistentes, as traduções e publicações a respeito desta dança, ficando os estudos restritos a escolas informais ${ }^{7}$ e algumas universidades. ${ }^{8}$ Este artigo, escrito por quem também pratica e ensina Contato Improvisação, vem a ser uma forma de apresentação e divulgação desta dança para a comunidade.

\section{O surgimento da dança contato improvisação}

A história do Contato Improvisação começa nos EUA no início dos anos 70. A iniciativa de pesquisa de movimentos partiu

3 Por exemplo: http://br.groups.yahoo.com/groupForum_de_contato_improvisacao/; http://www.contatoimproviso.net/; http://www.a-i-a.com/dci/;

http://users.lanminds.com/contact/; http://www.contactimprovisation.com/; http://www.contactimprovisation.ch/e/startseite/index.htm

http://contactimprovisation.co.uk/;

http://www.contactquarterly.com/links/cclinks.html

http://www.conexaodanca.art.br/estudoimp.htm;

http://www.sampa3.prodam.sp.gov.br/ccsp/linha/dart/revista8/entrevista.htm; http://www.facom.ufba.br/com024/contact/improvisation.html;

4 Há um calendário de eventos nos sites http://www.earthdance.net/calendar.htm e http://contactimprov.net/\#Events.

5 VIDEODA disponibiliza para venda e aluguel os vídeos de Contato Improvisação: Soft Pallet, Chute, Magnesium, Peripheral Vision, Fall After Newton e Contact at 10th \& 2nd (ver http://www.contactquarterly.com/vd/vd.html)

6 Ver a grande lista de artigos, teses e livros sobre Contato Improvisação no site http://contactimprov.net/biblio.html

7 Como o Estúdio Nova Dança e o Estúdio Move em São Paulo.

8 Como, por exemplo, há no Departamento de Artes Cênicas da Universidade de Brasília uma monografia de Diogo Túlio Wernik de Carvalho intitulada "Contato Improvisação - Implicações Metodológicas e Pedagógicas". Também a Universidade Federal da Bahia possui o Núcleo de Contato Improvisação da Escola de dade Federal da Bahia possui o Núcleo de Contato Improvisação da Escola de Dança, na Universidade do Rio de Janeiro a professora Dani Lima usa o Contato Improvisação na cadeira de Improvisação do Curso de Dança, na Universidade Anhembi Morumbi (SP) a professora Tica Lemos aborda Contato Improvisação nas disciplinas de Improvisação I e II, o Centro de Formação Profissional em Artes Circenses - CEFAC em São Paulo possui Contato Improvisação no currículo. Provavelmente nestes cursos há produção de monografias pelos alunos que não chegam a ser publicadas na forma de artigos ou livros acessíveis fora da biblioteca das respectivas universidades.

Movimento, Porto Alegre, v. 11, n. 2, p.89-110, maio/agosto de 2005 
de Steve Paxton, um bailarino com experiência em ginástica olímpica e Aikido' que vinha de uma trajetória de trabalho na dança moderna e experimental com Merce Cunningam, ${ }^{10}$ Robert Ellis Dunn, ${ }^{11}$ com as cooperativas de performances Judson Church Dance Theatre $^{12}$ e Grand Union. ${ }^{13}$ Ele estava interessado em descobrir como a improvisação em dança poderia facilitar a interação entre os corpos, as suas reações físicas e como proporcionar a participação igualitária das pessoas em um grupo, sem empregar arbitrariamente hierarquias sociais. Estava também empenhado em desenvolver um novo tipo de organização social para a dança, não ditatorial, não excludente, e em uma estrutura para a improvisação que não levasse ao isolamento de nenhum participante.

Influenciaram sua iniciativa as circunstâncias sociais e culturais da época e também idéias específicas de movimento. Paxton queria ampliar a noção de beleza física, até então muito restrita nas companhias de dança, e deixar o movimento derivar de uma outra base que não uma estética estabelecida ou um corpo tradicionalmente treinado. Porém não pressupunha a figura de um mestre a ser copiada pelos outros. Não queria eventos heróicos ou um vocabulário simbólico. Interessava-lhe o movimento do dia a dia, como a ação dos pedestres, o que se faz "aqui e agora", o que acontece no momento, a indeterminação. Aceitava qualquer material como um veículo de arte. Com isso buscava que a dança acontecesse por si e acreditava que qualquer corpo pudesse dançar. Empenhava-se também em encontrar a igualdade nos papéis de homens e mulheres na dança, considerando isso um importante valor social a ser integrado ao movimento e expresso nas performances.

9 Arte marcial japonesa que pode ser traduzida como a busca da harmonização espiritual. Tem forte influência da filosofia Zen Budista

10 Merce Cunningam, coreógrafo, bailarino e professor cuja filosofia estética causou mudanças na dança moderna. (Novack, 1990, p. 33).

11 Robert Ellis Dunn, músico associado a Cunningam que inspirou muitos coreó grafos da Judson Church por sua influência dada em aulas de composição em dança (Novack, 1990, p. 53).

12 Judson Church Dance Theatre (Dança Teatro Igreja Judson) foi uma cooperativa de performances no movimento de vanguarda da dança moderna experimental que existiu entre 1961 e 1964 em Nova lorque, e foi a mais representativa na manifestação e anunciação de mudanças sociais (Novack, 1990, p. 42).

13 Grand Union (Grande União) era uma cooperativa de livre improvisação em dança, teatro e música que existiu entre 70 e 76 (Novack, 1990, p. 53).

Movimento, Porto Alegre, v. 11, n. 2, p.89-110, maio/agosto de 2005 
Em janeiro de 1972, organizou uma performance com onze estudantes na Oberlin College (cidade de Oberlin, Ohio, Estados Unidos) chamada Magnesium. ${ }^{14}$ Esta performance foi gravada em vídeo e, de acordo com Novack (1990), o que nele se viu foram dez minutos onde homens cambaleavam saindo do seu eixo, colidiam entre si, caiam, rolavam e levantavam para se jogarem de novo, parecendo, às vezes, lutar. Os bailarinos focalizavam em si mesmos e não havia uma orientação para a platéia. A falta de controle caracterizava a maioria dos movimentos, quando o corpo era puxado ou lançado para fora do equilíbrio, caindo passivamente sobre outro corpo ou no chão. As quedas eram violentas, mas amortecidas por tatames sobre os quais rolavam assim que tocavam o chão. Depois deste jogo em alta velocidade o ritmo diminuía, os bailarinos paravam em pé de frente para diferentes direções e ficavam em uma suave oscilação radicalmente contrastante com o frenético momento anterior.

Meses depois Paxton foi convidado para fazer outras performances na John Weber Gallery em Nova Iorque, para as quais convidou estudantes ${ }^{15}$ que conheceu durante uma turnê com o grupo Grand Union, além da bailarina Barbara Dilley, da professora de release technique ${ }^{16}$ da Universidade de Rochester Mary Fulkerson e do cinegrafista Steve Christiansen. Este grupo viveu junto por dez dias investigando os dois extremos de desorientação física explorados em Magnesium: um extremo de lançar-se no espaço e em outra pessoa, e outro de estar em pé, parado e observando os menores impulsos de movimento no corpo (o que Paxton chamou de "Small Dance" e "Stand"). ${ }^{17}$ Rotineiramente eles testavam as possibilidades de dois corpos movendo-se juntos enquanto estavam em contato físico. Também praticavam release technique e treinavam aikido, experimentando os rolamentos, quedas e as habilidades dos parceiros nesta arte marcial. Buscavam desenvolver o conhecimento reflexo do corpo e uma estética baseada nos limites e necessidades físicas. Paxton chamou a dança de Contact Improvisation

14 Magnésio, metal leve.

15 Entre eles pessoas que tem importante papel no desenvolvimento do Contato Improvisação nos anos seguintes como Curt Sidall e Nancy Stark Smith que eram estudantes da Bennington College, Danny Lepkoff e David Woodberry que eram ambos alunos de Mary Fulkerson na Universidade de Rochester, Nita Little, estudante da Bennington College.

16 Técnica de relaxamento. Uma técnica de movimento baseada na imagem anatômica e que enfatiza a suavidade e o fluir do movimento.

17 Pequena Dança e Estar.

Movimento, Porto Alegre, v. 11, n. 2, p.89-110, maio/agosto de 2005 
porque exata e objetivamente descrevia o que eles estavam fazendo. Dos ensaios para as performances ficou registrado um vídeo chamado Chute, ${ }^{18}$ onde aparecem os bailarinos, homens e mulheres, dançando pela primeira vez Contato Improvisação. Novack (1990, p. 65 e 66) observou neste vídeo que os bailarinos apoiavam-se e equilibravam-se uns nos outros de uma maneira mais sustentada, suspendida, depois caíam, fazendo isto diversas vezes. Notou um grande relacionamento entre eles, geralmente divertido e delicado, fazendo das ações mais um ato de parceria do que um "ter tarefas a fazer". Usavam o corpo como um bloco só, mas também articulavam suas partes sucessivamente, como nos rolos do aikido. Usavam outras partes do corpo no chão como suporte, além dos pés e torso, como ombros, cabeça, quadris e mãos. Tanto em Magnesium quanto em Chute os dançarinos concentravam-se em sentir o movimento internamente mais do que em colocar seus corpos intencionalmente em formas particulares. Os desenhos no espaço feitos pela passagem dos corpos enquanto davam suporte para guiar ou impedir a queda do outro, eram espiralados através das três dimensões, adquirindo um senso esférico de espaço. Finalmente as performances se seguiram como uma continuação dos ensaios, durando em torno de cinco horas cada. A platéia vinha e ficava o quanto queria, não havia efeitos especiais de luz nem figurinos, música ou cenário, somente o tatame.

Em 1973 Paxton e mais Nita Little, Karen Radler, ${ }^{19}$ Curt Sidall, Nancy Stark Smith e Steve Christiansen fizeram uma turnê na costa oeste dos EUA que chamaram "You come. We'll show you what we $d o^{\prime \prime} .{ }^{20}$ No verão seguinte foram para a Itália, em Roma, apresentar-se na galeria L'Attico, onde outro vídeo foi feito: Soft Pallet. ${ }^{21}$ Neste vídeo há também o desenvolvimento de momentos solos onde o dançarino experimenta quedas e rolamentos. Sempre percebendo a sensação interna do movimento, há o deslocamento do suporte de uma parte do corpo para outra. É usado predominantemente o livre fluir do movimento gerado pelo peso passivo com ocasionais mudanças de direção. Isto indica o desenvolvimento daquilo que caracteriza o Contato Improvisação, um estilo de movimento que deriva dos duetos e da interação do grupo, mas que pode ser extrapolado experimentado por um dançarino sozinho.

18 Pára-quedas.

19 Estudante da Bennington College, em Bennington, Vermont.

20 "Você vem. Nós mostraremos a você o que nós fazemos".

21 Catre macio.

Movimento, Porto Alegre, v. 11, n. 2, p.89-1 10, maio/agosto de 2005 
Nos encontros que se sucederam começou a ficar impraticável ter sempre um tatame para amortecer as quedas, o que trouxe como conseqüência uma modificação no estilo atlético e de luta para a fluência de movimentos contínuos, controlados e com mais leveza no toque.

A respeito desta mudança houve um questionamento sobre a real existência de uma estética no Contato Improvisação. Sobre este aspecto, o comentário de Nancy Smith foi de que o trabalho tinha o foco na sensação, não em um estilo particular, nem em psicologia, estética, teatro ou emoções (Novack, 1990, p.68). Eles buscavam explorar os aspectos físicos do trabalho como um valor neutro: o que era possível fazer e não o que pareceria esteticamente. De acordo com Paxton, poderia se dizer que a estética ideal do Contato Improvisação é um corpo totalmente integrado (Novack, 1990, p.69).

Por viverem em lugares distantes uns dos outros, os contatistas (termo que designa os praticantes de Contato Improvisação) começaram a ensinar o que eles aprenderam para terem com quem continuar a investigar o estilo e dançar. Começaram então a passar a forma de dança adiante, por entendê-la com sendo de natureza popular e como uma demonstração de como o estilo em si precisa ser compartilhado. A natureza concisa desta forma de dança, o foco claro em manter contato físico com uma proposta de improvisação, de lidar com o equilíbrio, tornou possível sua rápida transmissão. Qualquer um poderia começar a praticar quase imediatamente, pois não havia um vocabulário a aprender como há nas técnicas de dança moderna. A ausência do objetivo de virtuosismo no Contato Improvisação fazia com que ele pudesse ser ensinado, pelo menos no início, rapidamente, em contraste com o longo tempo necessário para ensinar os princípios das outras danças em geral.

Por causa da sua base em noções físicas de sentir internamente o peso e o toque, o Contato Improvisação atraiu tanto bailarinos quanto não-bailarinos. Enquanto sua definição o restringe, ajudando a identificar e clarificar o que é Contato Improvisação, a sua concepção e ideologia o caracterizaram como aberto e livre, uma experimentação em pesquisa de movimento.

Nos anos seguintes o número de praticantes aumentou e sempre havia alguém novo para dançar, criando no ambiente um clima de imprevisibilidade, tensão e excitação. Dentro de uma estrutura convencionada como informal e solta, havia a intenção de exibir um comportamento como um processo, mais do que apresen-

Movimento, Porto Alegre, v. 11, n. 2, p.89-110, maio/agosto de 2005 
tar algo como um produto acabado. As performances eram como demonstrações e qualquer pessoa podia entrar. Nos encontros se fazia um círculo onde, no centro, duas pessoas começavam dançando até que um se separava do outro para fazer um solo, ou um terceiro intervinha para separá-los e formar outra dupla. Eventualmente se formava um trio, ou ainda outras pessoas entravam para dançar junto. Apesar de não ser convencionado ou requisitado, um que já tivesse dançado esperava até que todos dançassem para entrar novamente na roda. Dependendo das habilidades e reflexos dos participantes as performances continham alto grau de riscos físicos pelas quedas conseguintes aos suportes.

O público que vinha assistir as improvisações era cada vez maior. Danny Lepkoff lembra das reações da platéia com "uhhhs" e "ohhhhs" e risadas, como se estivessem vendo um jogo de basquete (Novack, 1990, p.72). O retorno que os contatistas recebiam do público demonstrava o quanto o Contato Improvisação havia misturado ou combinado a dança com o esporte e a arte com a socialização. Nancy S. Smith lembra que ouvia a respiração ou o suspiro da platéia quando havia uma queda, pois as pessoas não estavam acostumadas a ver isso a não ser como um acidente. Notava que saíam suadas, entusiasmadas, tensas ou emocionadas como se elas mesmas tivessem dançado. Lisa Nel$\operatorname{son}^{22}$ relatou que as pessoas da platéia saiam pulando umas nas outras, querendo rolar no chão, vinham abraçar os participantes, se penduravam neles. A sensação era de realmente ter havido uma troca, uma conexão, uma acessibilidade física entre público e dançarinos. O público estava presenciando com sensibilidade o surgimento de um estilo de movimento que, nestes primeiros eventos, era muito atlético e de alto risco. Uma dança cuja dinâmica baseava-se na interação e no senso de participação de grupo vivida e expressa de maneira informal.

Em 1975, praticamente todos os bailarinos que fizeram a turnê de 73 pela costa oeste dos EUA encontraram-se de novo na Califórnia e chamaram seu grupo de ReUnion. ${ }^{23}$ Além das performances, o grupo trocou idéias sobre o ensino da dança e discutiu suas experiências. Este diálogo sobre métodos de ensino

22 Lisa Nelson começou a praticar Contato Improvisação nos primeiros anos do seu surgimento, é co-editora da Contact Quarterly desde 1977, coreógrafa, seu surgimento, é co-editora da Conta
performer e parceira de Steve Paxton.

23 ReUnião.

Movimento, Porto Alegre, v. 11, n. 2, p.89-110, maio/agosto de 2005 
e vivências contribuiu muito para a evolução do Contato Improvisação como uma forma reconhecível. Com o tempo alguns exercícios tornaram-se freqüentes, reconhecíveis e definidos e quanto mais performances eram feitas, mais as pessoas identificavam tanto o estilo de movimento quanto o grupo com o nome Contact Improvisation. As técnicas de ensino também eram compartilhadas de boa vontade com outros professores. Os contatistas em geral concordavam que não havia um senso de posse sobre as técnicas, nem a necessidade de identificar quem as criou. As pessoas do ReUnion perceberam também que estavam juntas, engajadas em algo maior que um empreendimento temporário, e começaram a falar em formalização. Além disso, estavam preocupadas com os perigos do ensino e com a possível fragmentação e perda de reputação resultante da descontrolada difusão do Contato Improvisação. Paxton estava interessado em "controlar o ensino de sair do controle", de sair do equilíbrio, para que os participantes se protegessem contra lesões, pois estudantes relatavam torções, machucados nas articulações e dores agudas resultantes de aulas com professores desconhecidos (Novack, 1990, p.79). Isto fez com que se questionasse que tipo de atividades estavam sendo chamadas de Contato Improvisação. Em um boletim chamado Contact Newsletter, Paxton, descrevendo suas aulas, comentou sua insatisfação com os dançarinos que caminhavam em uma direção metafísica no trabalho com Contato Improvisação. Ele deu ênfase ao foco na sensação física no ensino do Contato Improvisação e ponderou que questões relacionadas ao misticismo, simbologia, psicologia, espiritualismo não eram adequadas (Novack, 1990, p.81). No ensino do Stand, discutindo momentum (produto do peso multiplicado pela velocidade) ou gravidade, cada professor deveria se fixar nos fatos sensoriais. Sua ênfase no físico como realidade, como um fenômeno natural, derivou do seu esforço em evitar que o Contato Improvisação se transformasse num veículo para investigações psíquicas ou encontros terapêuticos. Sua orientação ao físico constituía um compromisso com as raízes na filosofia da dança experimental dos anos sessenta e em parte da tradição da dança moderna.

Um escritor chamado Willian Schrievogel (conhecido como Koriel), que havia morado com alguns contatistas na época, ofereceu-se para ser uma espécie de administrador do Contato Improvisação ajudando a proteger o nome desta dança e a organizar suas atividades. Em um boletim publicado em abril de 75 ele sintetizou uma série de propostas, estabelecendo que a "companhia" (ReUnion) deveria comunicar-se com ele mensalmente,

Movimento, Porto Alegre, v. 11, n. 2, p.89-110, maio/agosto de 2005 
que dez por cento do que cada membro ganhasse fosse para um fundo e que os professores deveriam ter o aval de dois membros da companhia para poder ensinar. Além disso, cada professor deveria dar cinco por cento que ganhasse para o fundo. O boletim também incluía a proposta de Nita Little de que a companhia adotasse o nome de Contact Core (Centro de Contato) e que passasse a se usar "@ Steve Paxton et al." cada vez que a palavra "contact improvisation" fosse publicada.

Estas propostas, contudo, nunca foram postas em prática porque, ideologicamente, não estavam de acordo com o "espírito" do Contato Improvisação. Nancy Smith publicou um segundo boletim em novembro do mesmo ano, no qual escreveu que o grupo havia decidido desfazer a forma de comitê e não ter mais um administrador. Ao invés de serem "policiais" eles decidiram favorecer a comunicação entre todos os praticantes de contato, encorajando aqueles menos experientes a continuar praticando, mas aconselhando que parassem de ensinar por um tempo. Eles decidiram evitar fazer uma estrutura organizacional formal, mantendo um forte senso de que o que eles faziam era ad hoc e espontâneo, tanto a dança quanto a interação social nos encontros para a prática (jam session). ${ }^{24}$ Estas qualidades eram a marca registrada do Contato Improvisação. O que se fez foi, indiretamente e informalmente, manejar a necessidade de controle e de vigilância sobre o ensino, continuando com os boletins que em 1976 deram origem à revista Contact Quarterly.

A revista teve um impacto transformador no Contato Improvisação e o fez único entre as técnicas americanas de dança. Enquanto as outras técnicas de dança moderna têm as identidades consolidadas através de companhias lideradas por coreógrafos cujo nome dá também o nome da companhia (como, por exemplo, a de Merce Cunningam, Martha Grahan, Hanya Holm etc), o Contato Impro-

24 JAM: abreviatura de Jazz After Midnight, usada por músicos para designar encontros ou sessões de improvisação e adotada aqui pelos contatistas para seus encontros livres de Contato Improvisação.

25 A revista Contact Quarterly é publicada desde 1976 inicialmente com uma freqüência trimestral e atualmente numa frequencia semestral. E um projeto da Contact Collaborations, Inc, uma organização sem fins lucrativos do Estado de Nova York e é patrocinada parcialmente pelo Conselho Cultural de Massashussets. É uma revista especializada em dança indexada com ISSN: 0198-9634 é escrita em inglês, possui uma média de 100 páginas, custa dez dólares nos Estados Unidos e no Canadá e é distribuída também na Europa e pode ser exportada via assinatura por dois anos para todo o mundo. O escritório da CQ está localizado em Northampton, Massashussets, USA.

Movimento, Porto Alegre, v. 11, n. 2, p.89-110, maio/agosto de 2005 
visação consolidou-se através da prática em grupos e através dos escritos sobre isso. Pelo menos naquele período, o Contato era um exemplo de estrutura alternativa de organização em dança nos EUA. A revista proporcionou com sucesso uma conexão e um fórum de discussão sobre as atividades e idéias das pessoas. Veio para consolidar a existência de um movimento, de uma "comunidade" $^{\prime \prime}$ e de uma "rede de contato".

Embora Steve Paxton seja reconhecido como o fundador e guia original do Contato Improvisação, a técnica foi rapidamente se expandindo e se afastando do seu controle direto. Começou a haver uma diferenciação conforme a região, sendo feita na sua forma mais "pura" ou com experimentações teatrais. O desenvolvimento foi se dando com as organizações informais, com a revista Contact Quarterly, as viagens, a comunicação informal e, a partir de 76, com os freqüentes cursos intensivos e retiros. Também a imprensa e as agências de subvenção começaram a reconhecer o Contato Improvisação incentivando corporações, como organizações sem fins lucrativos, e estimulando as performances. Muitas pessoas passaram a escrever cartas e artigos para a revista, que aumentou sua tiragem de 350 exemplares, em 1977, para 1500, em 1980. ${ }^{26}$ Uma lista de contatos de praticantes no fim da revista possibilitou que as pessoas se comunicassem e pudessem se hospedar na casa de outros contatistas nas viagens. ${ }^{27}$ Em 1977 Steve Paxton, Lisa Nelson, Nancy Stark Smith, Danny Lepkoff, Roger Neece ${ }^{28}$ e Elizabeth Zimmer $^{29}$ criaram a Contact Collaborations Incorporation, uma corporação sem fins lucrativos para cuidar do trabalho na revista, das conferências e da manutenção do crescente arquivo de vídeos. Com esta organização a revista passou a ganhar auxílio da instituição americana de apoio às artes National Endowments for the Arts.

Em junho de 80 foi organizada uma conferência, "Improvisation: Dance as Art-Sport", ${ }^{30}$ na qual Steve Paxton era o palestrante principal. Dos participantes que vinham da Europa,

26 A tiragem do volume 30, número 2 de 2005 foi de 2500 exemplares.

27 Há 415 nomes de contatistas publicados na lista de contatos da Contact Quarterly Vol.29, No. 2 de 2004.

28 Contatista nascido em Boston que se interessava por administração e negócios.

29 Escritora de dança aficionada por Contato Improvisação, foi diretora da Associação Americana de Dança.

30 Improvisação: Dança como Arte-Esporte.

Movimento, Porto Alegre, v. 11, n. 2, p.89-110, maio/agosto de 2005 
Canadá e Estados Unidos, um terço praticava Contato Improvisação. Houve ainda uma conferência nacional de Contato Improvisação em 1983, organizada por Paxton e outros, chamada "Contact at 10th and 2nd in New York City at St. Mark's Church"." Foram nove noites de performances, um painel de discussões e uma grande jam session de Contato Improvisação. Foram discutidas coisas familiares aos anos iniciais, como a realidade física de transferência do peso, o valor da rede social e a natureza igualitária da forma de movimento. Falou-se menos em "deixar" a dança acontecer e abordaram-se temas que haviam sido "deixados de fora" e que deveriam agora ser incluídos, como a atenção às emoções, erotismo e intenções.

No decorrer da década de 80 o Contato Improvisação era a base para muitas performances, ajudando a moldar e transformar o estilo de movimento da dança teatro e formando a base para organizações de dança de natureza social como as jams e encontros regulares de dança "livre".

Novack (1990) lista características e valores centrais ao movimento do Contato Improvisação, assim como sua organização e estrutura performática: ${ }^{32}$ geração de movimentos através da mudança de pontos de contato entre corpos; percepção por meio da pele; foco na segmentação do corpo; movimentação em diversas direções simultaneamente; percepção interna do movimento; ênfase no peso e no fluxo; rolamento ao longo do corpo; uso do espaço em 360 graus; tácita inclusão da platéia informalidade intencional da apresentação exibida numa prática ou jam; entendimento do dançarino como uma pessoa comum; improvisação despida de intenções dramáticas; consciência de que todos são igualmente importantes.

Uma vez assumidas essas características do Contato Improvisação e identificando o corpo do contatista basicamente pela sua consciência e receptividade ao outro, surge uma questão qualitativa: como avaliar um dançarino, suas habilidades individuais e em relação aos outros? Particularmente nos anos iniciais, os dançarinos afirmavam a concepção do Contato Improvisação como uma "dança sem sentimento de culpa ou erro". Os dançarinos estavam teoricamente "livres de julgamentos", do peso de

31 Contato na Décima Rua com a Segunda Avenida da cidade de Nova lorque na Igreja São Marcos.

32 Novack guiou-se por conceitos de análise de movimento de Rudolf Laban (1971, 1974) e Irmgard Bartenieff (1980) (p.115 n2).

Movimento, Porto Alegre, v. 11, n. 2, p.89-110, maio/agosto de 2005 
ter de se tornar mestre ou não em alguma coisa. O maior interesse era simplesmente ter uma experiência com movimentos e com outras pessoas, por isso, o Contato Improvisação difere mais das artes marciais e se assemelha mais à dança social (como dançar rock and roll). Para os praticantes, a avaliação consistia em falar em quanto tempo se havia levado "para entrar na dança", isto é, para parar de se mover como tentativas. ${ }^{33}$ Consistia também em noticiar quem havia dançado com quem, pois havia o compromisso de se observar o decoro igualitário da dança: interação com o maior número de pessoas possível e que houvesse ao menos um duo de homens, outro de mulheres e outro de homem e mulher.

Hoje em dia se admite que com alguns parceiros seja mais fácil de dançar do que com outros. Se aceita o princípio que uma pessoa seja livre para dançar com qualquer um, mas com a preocupação de que ninguém seja deixado de fora. Deste modo, os novatos se sentem incluídos no grupo, e os mais experientes, no compromisso de dançar com todos. A capacidade de dançar com qualquer um caracteriza um improvisador avançado. Por se tratar de um diálogo físico entre dois dançarinos, toda dança apresenta um desafio único.

O clima de cooperação e apoio mútuo cultivado nos locais de Contato Improvisação encorajou muita gente (relutante em estudar outras formas de dança) a fazer Contato Improvisação. O conceito de "dança sem julgamentos" e a não separação por níveis de habilidades e experiências, ao menos em termos explícitos, intensificou a atmosfera das situações de muitas danças sociais e se contrapôs a virtualmente todos os ensinos de dança moderna e de ballet clássico, até dos amadores.

A minimização de avaliações padronizadas ou acadêmicas no Contato Improvisação também contribuiu para uma grande variação de "corpos aceitáveis" e hábeis para esta forma de dança. Podem ser contatistas pessoas das mais variadas idades, alturas, pesos, etnias, e, inclusive portadores de deficiências físicas. Esta diversidade de tipos de corpos contrasta com a uniformidade entre os bailarinos de outras formas de dança, onde padrões restritos de corpos e beleza prevalecem. A ideologia do Contato Improvisação define o dançarino em termos de ação e sensação do corpo e não de aparência. Isto promove a aceitação e inclusão de uma maior

33 A tentar induzir, comandar os movimentos ao invés de simplesmente deixá-los acontecer.

Movimento, Porto Alegre, v. 11, n. 2, p.89-110, maio/agosto de 2005 
variedade de talentos e de tipos de corpos. Oideal no Contato Improvisação é um íntimo e sincero diálogo entre duas pessoas por meio da interação entre seus corpos, cooperando com as leis da física e evocando imagens de camaradagem, jogo, brincadeira, educação, cuidado, esporte, sexo e amor.

\section{Contato improvisação: ensino e aprendizagem de uma dança}

A formação dos professores de Contato Improvisação não se dá em uma escola formal. Desde o surgimento desta dança, os princípios que a nortearam são compartilhados com todos aqueles que querem dançar, que assistem as performances de Contato Improvisação, participam das jams, das oficinas, conversam com as pessoas mais experientes, vêem os vídeos e lêem os artigos publicados. O ensino do Contato Improvisação acontece cada vez que uma pessoa compartilha com outras o que ela sabe sobre esta forma de movimento. O conhecimento transmitido informalmente é suficiente para que novos praticantes surjam. Por isso, praticamente todos que dançam Contato Improvisação são também professores (Hollowell \& Keriac, 1998).

Professores de Contato Improvisação não têm certificados, faixa preta, licenças ou diplomas. A disseminação do Contato Improvisação foi e ainda é realizada sem o benefício de uma escola formal de treinamento para professores, tutoria, ou programa de certificação. Todavia, há muitos contatistas que se tornaram professores "profissionais" e muitos outros que não derivam sua renda primária do ensino do contato, mas que são igualmente líderes dedicados em sua cidade. Alguns contatistas adquiriram uma boa reputação construída em muitos anos de prática, freqüentemente oferecendo exercícios altamente desenvolvidos que enfocam aspectos particulares desta forma de movimento.

Encontros de professores de Contato Improvisação são freqüentes em festivais, jams e retiros. Nestes encontros há conversas sobre o ensino do Contato Improvisação onde cada professor fala da sua experiência e ouve a dos colegas, se levantam questões sobre metodologias de ensino, preparação, treinamento, conduta e competência dos professores, currículo etc. É de costume este momento de diálogo, de troca de informações. Para as perguntas que são feitas não há alguém que tenha "a" resposta correta. Cada pessoa que ensina Contato Improvisação busca e acha as próprias respostas, encontra sua própria razão e

Movimento, Porto Alegre, v. 11, n. 2, p.89-110, maio/agosto de 2005 
permissão para ensinar da maneira que considera melhor. Cada pergunta e cada resposta é tema para reflexão e auto-avaliação.

Podem-se chamar estes encontros de "conferências pedagógicas" de Contato Improvisação, onde participam tanto professores iniciantes e experientes quanto os que não têm lecionado ou nunca lecionarão. Elas são o que os contatistas têm de mais parecido com uma autoridade central, porém possui uma postura de anti-autoridade. É um espaço aberto e seguro para se admitir que não se conhecem todas as respostas, mas as que cada um encontra são compartilhadas. Assim não se pretende designar um "modo certo" para ensinar Contato Improvisação. Os assuntos problemáticos ou difíceis são enfrentados numa atmosfera encorajadora. Os contatistas procuram saber de outras experiências, opiniões e conceitos e focalizam-se nas preocupações e interesses comuns.

Na aprendizagem do Contato Improvisação, uma pessoa adquire a prática mais em um jeito de se mover do que em executar um grupo particular de movimentos. Embora haja diferenças entre os professores, todos eles instruem seus alunos a focalizar na sensação interna do toque, do contato e da pressão do peso dos corpos. Desta maneira, no processo de aprendizagem, o sentido do toque, a propriocepção e as ações de reflexo físico assumem maior importância para o dançarino do que o sentido da visão e escolhas conscientes de ações. Pode-se entender esta estratégia como não tradicional uma vez que, como colocado em Fortin (1998), “a 'aprendizagem da observação' sustenta um conservadorismo do ensino", onde os professores repetem aquilo que aprenderam com seus professores, mantendo imagens difíceis de superar e seguindo, assim, uma maneira tacitamente aceita de "pensar" e "fazer". Quando se faz Contato Improvisação, a chave para ser um bom parceiro está na consciência de movimento de cada um dentro dos parâmetros da forma desta dança.

O estudante, além de se sensibilizar ao peso e toque, deve aceitar a desorientação e aprender a lidar com situações, como a de ser virado de cabeça para baixo. Os contatistas praticam quedas, rolamentos, inversões e sustentam o peso com diferentes partes do corpo. São sustentados, suspendidos, entregam e relaxam o corpo e usam a visão periférica, tendo nos olhos um foco mais amplo e geral do que específico ou direcionado. Podem praticar sozinhos ou em duplas, utilizar diferentes materiais, como bolas, móveis e atuar em locais como espaços públicos urbanos, árvores etc. O professor raramente demonstra um movimento para ser copiado precisamente.

Movimento, Porto Alegre, v. 11, n. 2, p.89-110, maio/agosto de 2005 
Muitos professores são formados em alguma técnica de educação somática, ${ }^{34}$ que é aplicada também em suas aulas de Contato Improvisação. São consideradas técnicas de educação somática Body-Mind Centering ${ }^{\circledR},{ }^{35}$ Ideokinesis, ${ }^{36}$ Alexander Technique, ${ }^{37}$ Eutonia ${ }^{38}$ Feldenkrais, ${ }^{39}$ Cadeias Musculares e Articulares Método G.D.S. ${ }^{40}$ entre outras. A abordagem somática tem uma perspectiva mais globalizada do ser humano e trabalha o corpo através de uma concepção de unidade complexa e perceptiva. Assim, como no modelo somático, no Contato Improvisação a ênfase é dada às percepções internas do indivíduo usando mais a propriocepção do que a visão. O centro é o estudante, que se encarrega de sua própria aprendizagem, sendo o saber construído a partir da própria experiência.

Apesar de Contato Improvisação ser, por definição, uma forma de dança espontânea, alguns exemplos de itens abordados nas práticas ilustram um pouco a diversidade de possibilidades de condução do ensino. ${ }^{41}$

34 Segundo Thomas Hanna (1983, p.1 in Fortin, 1996) e educação somática é: "a art e a ciência de um processo relacional interno entre a consciência, o biológico e o meio ambiente, estes três fatores sendo vistos como um todo agindo em sinergia".

35 The School for Body-Mind Centering ${ }^{\circledR}$ está localizada em Massachussets, nos Estados Unidos e tem Bonnie Bainbridge Cohen como Diretora Educacional. Estados Unidos te Entre os objetivos desta escola está a busca do entendimento de como a mente expressada através do corpo em movimento. Um aspecto importante no BMC e descobrir a relação entre o menor nivel de atividade dentro do corpo e o maio movimento do corpo, associando, por exemplo, o movimento intracelular com expressão externa do movimento no espaço. (www.bodymindcentering.com).

36 É uma disciplina que emprega o uso de imagens como um recurso para melhorar padrões musculares. Foi inicialmente desenvolvido por Mabel E. todd. Se primeiro livro "The Thinking Body" foi publicado em 1937. (Contact Quarterly, Vol $22 \# 2,1997$. p. 24)

37 Técnica prática baseada na experiência e observação individuais criada por Frederick Matthias Alexander para aliviar tensões, reeducar a movimentação muscular modificando e aprimorando as execuções. (www.abtalexander.com.br)

38 Criada por Gerda Alexander, basicamente trabalha sobre um equilíbrio consciente das tensões para que qualquer movimento seja efetuado com um mínimo de energia e um máximo de eficácia. (Brieghel-Müller, 1987. p. V e VII).

39 Criado pelo pesquisador israelense Moshe Feldenkrais, é um método de educação somática que utiliza as percepções que o movimento do corpo no espaço para tornar mais eficientes e econômicos os movimentos que integram o dia a dia (www.feldenkrais.org.br).

40 Desenvolvido pela fisioterapeuta belga Godelieve Denys-Struyf, o método de cadeias musculares e articulares estruturou-se com base nos pressupostos teocadei mútodos de Facilitacão Neuromuscular Proprioceptiva, Mezierista e de ricos dos métodos de Facilitação Neuromus

41 Não seria possível descrever detalhadamente cada um destes exemplos nas poucas páginas deste artigo. Eles são citados aqui apenas como uma ilustração.

Movimento, Porto Alegre, v. 11, n. 2, p.89-110, maio/agosto de 2005 
Na página da web http://www.shakti.egr.duke.edu/contact acessada em 16 de novembro de 1999, há o relato de uma série de atividades, praticadas em encontros semanais de Contato Improvisação por um grupo na Duke University, em Durhan, EUA, que abordam "princípios gerais designados para promover um pouco de segurança e abrir possibilidades para movimentos interessantes". São exercícios direcionados a diferentes objetivos: preparar para se mover, "quebrar o gelo" do medo de tocar, criar segurança e confiança, encontrar e testar o centro de equilíbrio do corpo, aprender a cair, rolar, ficar de cabeça para baixo, sensibilizar os pontos de contato, fazer transições, subidas e suportes, experimentar estilos de se mover, sentir o momentum e experimentar com uso de objetos e adereços. ${ }^{42}$

No periódico Contact Quarterly (Fall 89, vol., 15 \#1, p. 39), Jerry Zientara anotou uma lista de elementos - conceitos, exercícios, habilidades e atitudes - que deveriam ser incluídas num curso básico de Contato Improvisação. Estas notas foram feitas na After ArtSport Conference, ${ }^{44}$ Minneapolis, em junho de 80 . Sem estar em uma ordem especial, esta lista inclui: alinhamento, massagem e manipulação do corpo, o Estar e a Pequena Dança, o espiritual ou sensação íntima do trabalho, compaixão, "ser" mais preferivelmente que "fazer", queda, jogo e diversão, orientação espacial, aquecimento no chão, condição de neutralidade, entrada e saída da dança, história do Contato Improvisação, respiração, relaxamento, aquecimento, segurança, confiança, alongamento da parte posterior do corpo, contrabalanços, como escutar o corpo, conforto do movimento, costume de fazer um feedback positivo, uso de imagens, jargão do contato, cinesiologia e anatomia, busca do ponto de contato, conexão, transferência, rolamentos, equilíbrio, instruções ambíguas.

Steve Paxton, em uma aula transcrita e publicada na Contact Quarterly (Vol. 11 \#1, Winter 86, p. 48 a 50), se utiliza de palavras e indicações como: relaxe, respire, intua, imagine, a massa deve ser a sensação mais importante, o sentimento da gravidade, faça menor, a pequena dança, compartilhe o ponto de equilíbrio, deixe o movimento levá-lo, nada está errado, visão periférica, (perguntas em relação ao estado de cada um), conforto, não dirija, o corpo sabe e quer jogar e brincar, massageie, torça, lubrifique, deixe fluir, mais lento, mais rápido etc.

42/43 As sugestões de exercícios para facilitar a aprendizagem estão detalhados no site citado.

44 Depois da Conferência de Arte-Esporte.

Movimento, Porto Alegre, v. 11, n. 2, p.89-110, maio/agosto de 2005 
Tica Lemos, ${ }^{45}$ considerada por muitos a introdutora do Contato Improvisação no Brasil, entregou um texto em uma oficina $^{46}$ onde descrevia, além de uma definição de Contato Improvisação e o objetivo da oficina, alguns conceitos, objetivos e pensamentos que compõem o estilo, como por exemplo: definição de improvisação, improvisar, estar presente, aikido, ki, campo áurico, chakras, física, Ideokinesis. ${ }^{47}$ Também fez uso de um esqueleto para auxiliar a imagem interna dos ossos e articulações e mostrou o vídeo "Fall After Newton". ${ }^{48}$

Em artigo publicado na Contact Quarterly (V. 17, n.2, 1992. p. 67-68), o contatista John Marinelli ${ }^{49}$ relata questões abordadas em um curso realizado no México, ${ }^{50}$ tais como: o senso proprioceptivo, o cinestésico, a (des)orientação vestibular, a troca de peso, o alinhamento com a gravidade, momentum e impulsos de movimentos, a continuidade de mudança de pontos de contato físico, o dar e o receber peso, aprendizagem da arte de controlar uma queda livre, a escuta com o corpo, os elementos de água, ar, terra, fogo, éter (técnica introduzida por Nancy Stark Smith), danças abertas e discussões, habilidades mais avançadas como correr e jogar-se no outro, subidas dinâmicas e técnicas de parada-de-mão.

45 Tica Lemos tomou conhecimento do Contato Improvisação em meados da década de 80 , em Londres, quando assistiu a uma performance de Steve Paxton, Simone Forty e Kirstie Simpson. A partir daí procurou orientar sua carreira com base nessa técnica. Fez vários workshops de improvisação na Inglaterra. Quando entrou na School of New Dance Development, na Holanda, teve contato direto com Steve Paxton e Lisa Nelson. Depois de formada, em julho de 1987, foi para os Estados Unidos, onde conheceu várias pessoas que trabalhavam com Contato Improvisação tendo, inclusive, estreitado o relacionamento com Steve e Lisa. Quando retornou ao Brasil, no final de 1987, trazia na bagagem, além da sua própria experiência, vídeos e publicações sobre Contact Improvisation. Em 1995 propria experiência, videos eublicaçoes sobre Contact Improvisation. Em 1995 Dança em São Paulo.

46 Oficina de Contato Improvisação no Festival de Dança do Triângulo, em Uberlândia, MG, em julho de 2002.

47 Eu participei desta e de outras oficinas com Tica Lemos. Suas aulas duram em torno de duas horas e ela costumava praticar Ideokinesis e aikido como ferramentas para facilitar a dança.

48 Queda depois de Newton. Um vídeo de 23 minutos que mostra o Contato Improvisação de 1972 a 1983 com Nancy Stark Smith e narração e análise de Steve Paxton.

49 Desde 1977 estuda, pratica e dança Contato Improvisação. Fez mestrado em Estudos do Movimento na Wesleyan University, Connecticut e é certificado como professor de Alexander Technique.

50 Este curso durou três semanas. Na revista ele descreve e justifica seus objetivos, exercícios e sua opinião sobre o resultado obtido com os alunos.

Movimento, Porto Alegre, v. 11, n. 2, p.89-1 10, maio/agosto de 2005 
Também fez uma jam com estudantes e profissionais juntos e deixou quatro números da Contact Quarterly e o livro de Cynthia Novack, Sharing the Dance, disponível aos alunos.

Para os contatistas, a inexistência de uma fonte centralizadora de autoridade que determine o que é apropriado em termos de currículo ou de metodologia pedagógica em Contato Improvisação estimula uma curiosidade ativa, opiniões controversas, e uma procura não só por respostas, mas também por questionamentos relevantes. Cada professor se responsabiliza por definir padrões e estabelecer valores. As escolhas pedagógicas são analisadas tanto pelos próprios alunos ao final de uma aula quanto pelos outros professores na exposição dos métodos de cada um. Assim, a direção e o futuro do Contato Improvisação é traçado a partir das experiências individuais e decidido coletivamente.

\section{Considerações finais}

O Contato Improvisação é uma prática que já existe há mais de trinta anos e possui praticantes nos Estados Unidos, América Latina, Canadá, Europa, Austrália, China, Japão, Israel e Nova Zelândia. É um estilo de movimento que vem se desenvolvendo pelo diálogo estabelecido entre seus praticantes, seja no contato direto da dança ou no contato indireto, por meio das publicações e sites da internet onde se trocam experiências e estudos.

A comunicação estabelecida através do diálogo é a essência desta dança, tanto na prática em si, com o diálogo corporal, quanto no desenvolvimento de métodos de ensino e no desenvolvimento técnico, com o diálogo verbal. O diálogo acontece em vários níveis e sentidos: no indivíduo com seu próprio corpo; no corpo do indivíduo com o ambiente; no corpo de um indivíduo com outro indivíduo com quem se relaciona corporalmente; no diálogo verbal entre contatistas sobre seus métodos de ensino, relato de experiências, questionamentos; no diálogo entre o Contato Improvisação e outras técnicas de educação somática, bem como de outras expressões do movimento humano (como teatro, danças sociais, dança moderna, artes marciais etc.).

Os praticantes de Contato Improvisação optaram por uma "institucionalização informal", não centralizadora nem autoritária sobre esta dança, que se desenvolveu tendo como princípio aquilo que caracteriza a improvisação: o estado de presença e consciência a respeito das decisões e do fluxo dos acontecimentos. A técnica evoluiu não a partir da repetição de um padrão

Movimento, Porto Alegre, v. 11, n. 2, p.89-110, maio/agosto de 2005 
formal de movimentos, e sim a partir da sensação, da relação sensório-motora. Assim, improvisação não é sinônimo de desorganização. Os praticantes de Contato Improvisação organizamse norteados por regras básicas, algumas criadas nos primórdios da sua origem e outras criadas pelas necessidades que foram surgindo com o tempo, com o aumento da experiência e do número de praticantes. Basicamente estas regras são aprender a dar e receber o peso, seguir os pontos de contato, se desorientar, relaxar, cair e rolar. Estas regras dizem respeito também ao cuidado e à responsabilidade consigo e com o outro, à consciência corporal, à percepção e observação dos limites físicos, à espontaneidade, à generosidade, ao prazer, à liberdade, à inclusão e à cooperação. Com estes princípios o Contato Improvisação é identificável pelo valor de seus códigos de conduta e assim instituído como uma arte socializadora, popular, agregativa, democrática e cooperativa. Estes princípios são regularmente aplicados nas jams sessions de Contato Improvisação, que são abertas ao público e acontecem com freqüência semanal, quinzenal, mensal, semestral ou anual em cada cidade onde há contatistas atuantes.

Os contatistas, mesmo os mais experientes, procuram manter um espírito de principiante, pois acreditam que toda vez que se dança há um potencial para aprender. Ao se "compartilhar a dança", pode-se encontrar no outro não apenas o que ele tem para oferecer neste momento, mas também a sabedoria por ele acumulada em todas as danças já compartilhadas antes. Muita aprendizagem simplesmente acontece também na auto-observação, prestando atenção na dança de si mesmo. Às vezes um iniciante pode fazer uma observação que um dançarino experiente negligenciou ao longo de anos. Por essa mentalidade de inclusão e mistura de diferentes níveis de experiências e habilidades, bem como de diferentes tipos de corpos, muitas pessoas se sentem estimuladas a dançar Contato Improvisação. Desta forma é valorizada tanto a diversidade de corpos quanto a diversidade de formação de cada indivíduo.

O Contato Improvisação é uma forma de movimento que não entra em um sistema de alto rendimento, virtuosismo e conquista de prêmios, ou seja, não é uma dança de competição. Pelo contrário, o dançarino se desenvolve cooperando com os parceiros e atento à aprendizagem que pode ter com cada um.

Mesmo não possuindo escolas formais, o Contato Improvisação está cada vez mais presente nas universidades, seja como

Movimento, Porto Alegre, v. 11, n. 2, p.89-1 10, maio/agosto de 2005 
uma experimentação de movimento em uma disciplina prática, como parte da história da dança contemporânea ou como tema de monografias, dissertações e teses. Isto demonstra um reconhecimento da sua importância e relevância no panorama da dança mundial nas três últimas décadas.

Para dar continuidade a esse trabalho seria interessante desenvolver um estudo sobre os significados atuais da prática do Contato Improvisação em pessoas que vivem no Brasil, ou ainda discutindo mais profundamente os aspectos do ensino e aprendizagem desta forma de dança contextualizada na cultura local.

\begin{tabular}{l}
\hline Contacto improvisación (contact improvisation) \\
- un diálogo en danza - \\
Resumen: Este estudio es una revisión bibliográfica que \\
presenta el Contact Improvisation (Cl), un estilo del danza \\
creado en el inicio de los años setenta en EE.UU. y que se \\
ha desarrollado en varios países, como una práctica cuyos \\
principios traen cambios de modelos en la danza y \\
abordan discusiones actuales sobre cuerpo, educación, \\
género, sexualidad, identidad y diferencia. Sobre el \\
Contact Improvisation existe una producción intelectual \\
significativa materializada en un periódico específico prin- \\
cipal (Contact Quarterly), revistas y periódicos de \\
danza, páginas de internet, videos, teorías y libros además \\
de seminarios y festivales. \\
Palabra-clave: danza, cuerpo, educación.
\end{tabular}

\section{Contact improvisation (a dialogue in dance)}

Abstract: This research is a bibliographic review about Contact Improvisation, a dance created in USA in the seventies that is being developed in many countries as a practice with principles that brings changes of patterns in dance and which discusses body, education, gender questions, sexuality, identity and difference. There are a significant number of researches about Contact Improvisation as the publications in the journal Contact Quarterly, other dance magazines and journals, internet sites, videos, papers, books, seminars and festivals.

Keywords: dance, body, education. 


\section{Referências}

ALEXANDER TECHNIQUE. http://www.abtalexander.com.br. Acessado em 14 de março de 2005.

BERNARD, André. Ideokinesis \& Creative Boby Aligment. Contact Quarterly. Contact Collaborations. Northampton, MA, USA. V. 22, n. 2, p.24, summer/fall, 1997.

BODY MIND CENTERING. Disponível em http: //www.bodymindcentering.com, acessado em 24/04/2004.

BRIEGHEL-MÜLLER, Gunna. Eutonia e Relaxamento - relaxamento corporal e mental. São Paulo, Manole: 1987.

DAÓLIO, Jocimar. A Antropologia Social e a Educação Física: possibilidades de encontro. In: CARVALHO, Yara e RUBIO, Katia. Educação Física e Ciências Humanas. São Paulo: Hucitec, 2001

FELDENKRAIS. http://www.feldenkrais.org.br, Acessado em 14 de março de 2005.

FORTIN, Sylvie. Educação somática: Novo ingrediente da formação prática em dança. Tradução Márcia Strazacappa. Nouvelles de Dance, 28, p. 15-30, 1996.

Quando a ciência da dança e a educação somática entram em uma aula técnica de dança. Pró-Posições - Vol.9 no 2(26). Unicamp, Campinas, São Paulo. Junho de 1998.

HOLLOWELL, Leigh \& KERIAC. Contato Improvisação 25 anos - 0 trilho do ensino. Tradução e adaptação de Camillo Vacalebre.. Artigo publicado no "Contact Quarterly - a vehicle for moving ideas" - Edição Inverno/Primavera 1998, Volume 23, n. 1. Disponível em http://br.groups.yahoo.com/group/ Forum_de_contato_improvisacao/ acessado em 15/04/2005.

IMPROVISATION.Disponível em http://www.facom.ufba.br/com024/contact/ artigo1.html, acessado em 24/04/2004.

MARINELLI, John. Making Contact in México. Contact Quarterly. Contact Collaborations. Northampton, MA, USA. V. 17, n. 2, p.67-68, summer/fall, 1992

MORIN, Edgard. Epistemologia da complexidade. In: Schnitman, Dora Fried (Org.) Novos paradigmas, cultura e subjetividade. Porto Alegre: Artes Médicas, 1996. p.275-286

NOVACK, Cynthia. Sharing the dance: contact improvisation and american culture. Madison, Wiscotin: The University of Wiscontin Press, 1990.

PAXTON, Steve. Transcription. Contact Quarterly. Contact Collaborations. Northampton, MA, USA. V. 11, n. 1, p.48-50, winter, 1986.

TECHNIQUES OF CONTACT IMPROVISATION. Disponível em http://www.shakti.egr.duke.edu/contact/, acessado em 16 de novembro de 1999.

Movimento, Porto Alegre, v. 11, n. 2, p.89-110, maio/agosto de 2005 
110 Emfoco

Fernanda Hübner de Carvalho Leite

VIEIRA, Adriane. O método de cadeias musculares e articulares de G.D.S.:

uma abordagem somática. Revista Movimento. Ano IV- No 8 -1998/1.

ZIENTARA, Jerry. Basic Contact List. Contact Quarterly. Contact Collaborations. Northampton, MA, USA. V. 15, n. 1, p. 39, fall, 1989. 